\title{
Functional Analysis of Aldehyde Oxidase Using Expressed Chimeric Enzyme between Monkey and Rat
}

\author{
Kunio ItoH, ${ }^{a}$ Tasuku Asakawa, ${ }^{a}$ Kouichi Hoshino, ${ }^{a}$ Mayuko Adachi, ${ }^{a}$ Kensuke FukiYa, ${ }^{a}$ \\ Nobuaki WATANABE, ${ }^{b}$ and Yorihisa TANAKA ${ }^{*, a}$ \\ ${ }^{a}$ Department of Drug Metabolism and Pharmacokinetics, Tohoku Pharmaceutical University; 4-4-1 Komatsushima, \\ Aoba-ku, Sendai 981-8558, Japan: and ${ }^{b}$ Drug Metabolism and Pharmacokinetics Research Laboratories, Daiichi-Sankyo \\ Co., Ltd.; 1-2-58 Hiromachi, Shinagawa-ku, Tokyo 140-8710, Japan. \\ Received August 1, 2008; accepted November 5, 2008; published online November 6, 2008
}

\begin{abstract}
Aldehyde oxidase (AO) is a homodimer with a subunit molecular mass of approximately $150 \mathrm{kDa}$. Each subunit consists of about $20 \mathrm{kDa} 2 \mathrm{Fe}-2 \mathrm{~S}$ cluster domain storing reducing equivalents, about $40 \mathrm{kDa}$ flavine adenine dinucleotide (FAD) domain and about $85 \mathrm{kDa}$ molybdenum cofactor (MoCo) domain containing a substrate binding site. In order to clarify the properties of each domain, especially substrate binding domain, chimeric cDNAs were constructed by mutual exchange of $2 \mathrm{Fe}-2 \mathrm{~S} / \mathrm{FAD}$ and MoCo domains between monkey and rat. Chimeric monkey/rat AO was referred to one with monkey type 2Fe-2S/FAD domains and a rat type MoCo domain. Rat/monkey AO was vice versa. AO-catalyzed 2-oxidation activities of $(S)$-RS-8359 were measured using the expressed enzyme in Escherichia coli. Substrate inhibition was seen in rat $\mathrm{AO}$ and chimeric monkey/rat $\mathrm{AO}$, but not in monkey $\mathrm{AO}$ and chimeric rat/monkey $\mathrm{AO}$, suggesting that the phenomenon might be dependent on the natures of MoCo domain of rat. A biphasic Eadie-Hofstee profile was observed in monkey AO and chimeric rat/monkey $\mathrm{AO}$, but not rat $\mathrm{AO}$ and chimeric monkey/rat $\mathrm{AO}$, indicating that the biphasic profile might be related to the properties of MoCo domain of monkey. Two-fold greater $V_{\max }$ values were observed in monkey AO than in chimeric rat/monkey AO, and in chimeric monkey/rat AO than in rat AO, suggesting that monkey has the more effective electron transfer system than rat. Thus, the use of chimeric enzymes revealed that 2Fe-2S/FAD and MoCo domains affect the velocity and the quantitative profiles of AO-catalyzed $(S)$-RS-8359 2-oxidation, respectively.
\end{abstract}

Key words aldehyde oxidase; chimeric enzyme; monkey; rat; Escherichia coli expression

Aldehyde oxidase (AO, EC 1.2.3.1) and xanthine oxidase are major members of the molybdenum hydroxylase family. Both enzymes consist of a homodimer with a subunit molecular mass of about $150 \mathrm{kDa}$. Each subunit is made up of a $20 \mathrm{kDa}$ domain containing two different $2 \mathrm{Fe}-2 \mathrm{~S}$ clusters in which reducing equivalents necessary for catalysis are stored, a $40 \mathrm{kDa}$ domain containing a flavine adenine dinucleotide (FAD), and an $80 \mathrm{kDa}$ domain containing a molybdenum cofactor $(\mathrm{MoCo})$ in which a substrate binding site is located. ${ }^{1)}$ $\mathrm{AO}$ catalyzes the oxidation of a wide range of endogenous and exogenous aldehydes and $\mathrm{N}$-heterocyclic aromatic compounds. The representative $N$-heterocyclic-containing drugs that serve as substrates for $\mathrm{AO}$ are famciclovir, methotrexate, 6-mercaptopurine, and cinchona alkaloids. ${ }^{1-6)}$ In addition, the atypical antipsychotic drug, ziprasidone, is mainly metabolized by AO-catalyzed reductive ring cleavage in human. ${ }^{7,8)}$

$\mathrm{AO}$ has several pharmacokinetically interesting properties of remarkable species differences, large strain differences in rat, and individual differences in some kinds of rat strains. Among those phenomena, species differences have been widely demonstrated in the metabolism of many drugs catalyzed by AO. They include an ocular hypotensive agent, brimonidine, ${ }^{9)}$ antiviral drugs, famciclovir and 6-deoxypenciclovir, ${ }^{10)}$ an antineoplastic drug, methotrexate, ${ }^{11)}$ an ultrashort acting hypnotic, zaleplon, ${ }^{12)}$ and an oral antitumor agent, zebularine. ${ }^{13)}$ Thus, it is now well established that the variations in $\mathrm{AO}$ activity may be dependent on not only animal species, but also on the chemical structure of the substrate. Roughly speaking, $\mathrm{AO}$ activity is high in monkeys and humans, moderate to low in rats and mice, and deficient in dogs. Similar to those reports, we observed remarkable species differences, rat strain differences, and polymorphism-based individual differences in Donryu strain rat in the AO-catalyzed 2-oxidation activity of the $(S)$-enantiomer of RS-8359, [( \pm )-4-(4-cyanoanilino)-5,6-dihydro-7-hydroxy$7 H$-cyclopenta $[d]$-pyrimidine.$^{14-18)}$ The compound is a reversible and selective monoamine oxidase (MAO)-A inhibitor ${ }^{19,20)}$ and has been developed as an anti-depressant. ${ }^{21,22)}$ As to species differences, monkeys showed the highest activity followed by humans. Furthermore, monkey and human liver cytosol preparations exhibited a biphasic pattern in the Eadie-Hofstee plots for the 2-oxidation activity of $(S)$-RS8359 , but not rat and mouse liver cytosols. The expression system of monkey AO full cDNA suggested that the biphasic Eadie-Hofstee profile might be produced by the existence of two active sites in a single $\mathrm{AO}$ enzyme rather than by the existence of two AO isoforms. ${ }^{23)}$

Molecular cloning of AO cDNA has been accomplished in mouse, ${ }^{24,25)}$ rat $^{26)}$ rabbit ${ }^{27)}$ bovine, ${ }^{28)}$ and human. ${ }^{29-31)}$ The deduced primary structure of AO proteins have been characterized with regard to consensus sequences for two distinct $2 \mathrm{Fe}-2 \mathrm{~S}$ clusters and five MoCo-binding sites. Wright et al. ${ }^{26)}$ indicated that the kinetic differences of $\mathrm{AO}$ activity between male and female rats are due to sensitivity to redox manipulation of $\mathrm{AO}$ that was most likely expressed by a single $\mathrm{AO}$ gene. In human ${ }^{32)}$ and mouse, ${ }^{33)}$ the structures of the $5^{\prime}$ flanking region containing several putative regulatory elements were determined. In spite of this rapid progress in molecular biology of $\mathrm{AO}$, little is known about the mechanisms of variation in AO activity depending on both of animal species and chemical structure of substrate. Modification of 
the specific amino acid of an enzyme by site-directed mutagenesis (SDM) may be one of the best ways to clearly reveal the various properties of the enzyme. Before conducting SDM, in the current study we constructed chimeric AOs between monkey and rat, and investigated their catalytic activities in order to obtain some information on the properties of each domain of $\mathrm{AO}$.

\section{MATERIALS AND METHODS}

Chemicals and Reagents The $(S)$-enantiomer of RS8359 and its 2-keto metabolite were supplied by Ube Kosan Co., Ltd. (Yamaguchi, Japan). Hydrocortisone, an internal standard of HPLC analysis, was purchased from Sigma Chemical Co. (St. Louis, MO, U.S.A.). Imidazole, sodium molybdic(VI) acid $\left(\mathrm{Na}_{2} \mathrm{MoO}_{4}\right)$, and isopropyl- $\beta$ - $\mathrm{D}(-)$-thiogalactopyranoside (IPTG) were obtained from Wako Pure Chemical Industries, Ltd. (Osaka, Japan). All other reagents were of reagent grade. Anti-His-tag antiserum was purchased from Medical \& Biological Laboratories Co., Ltd. (Nagoya, Japan).

Enzyme Activity Assay (S)-RS-8359 (0.313-300 $\mu \mathrm{M})$ was incubated at $37^{\circ} \mathrm{C}$ for $60 \mathrm{~min}$ in a reaction mixture $(0.25 \mathrm{ml})$ consisting of $100 \mathrm{~mm}$ phosphate buffer ( $\mathrm{pH} 6.0)$, $1.0 \mathrm{~mm} \mathrm{~K} \mathrm{~K}_{3} \mathrm{Fe}(\mathrm{CN})_{6}, 0.13 \mathrm{~mm}$ EDTA, and the expressed protein $(5-20 \mu \mathrm{g} / \mathrm{ml}, 0.10 \mathrm{ml})$. The reaction was stopped by the addition of acetonitrile $(0.50 \mathrm{ml})$ containing $0.2 \mathrm{mg} / \mathrm{ml}$ of hydrocortisone as an internal standard. The mixture was then centrifuged at $10000 \boldsymbol{g}$ for $5 \mathrm{~min}$. Aliquots $(25 \mu \mathrm{l})$ of the supernatant were analyzed for quantification of the oxidation product by reversed-phase HPLC on a YMC ODS A-312 column $(6.0 \mathrm{~mm}$ i.d. $\times 150 \mathrm{~mm}$, YMC Co., Ltd., Kyoto, Japan). The mobile phase was composed of acetonitrile $/ 0.5 \%$ ammonium acetate $(25: 75)$; the flow rate was $1.0 \mathrm{ml} / \mathrm{min}$. The HPLC instrument was a Shimadzu model 6A High Performance Liquid Chromatograph System (Shimadzu Seisakusho Co., Ltd., Kyoto, Japan). The peaks were monitored for absorbance at $315 \mathrm{~nm}$; the peak area was calculated on a Chromatopac C-R4A (Shimadzu).

Kinetic parameters were estimated using the nonlinear regression function in Sigma Plot (version 6.0). The standard Michaelis-Menten velocity equation and the single-enzyme model with two binding sites described by Korzekwa et al. ${ }^{34)}$ was used for the analysis of monophasic and biphasic data shown in Eadie-Hofstee plots, respectively.

Construction of Expression System for Chimeric AO between Monkey and Donryu Strain Rat AO cDNAs of monkey ${ }^{23)}$ and Donryu strain rat $^{35)}$ have already been subcloned and cryopreserved in pQE-30Xa vector (QIAGEN, Venlo, The Netherlands) in this laboratory. The strategy of constructing chimeric AO between monkey and Donryu strain rat is illustrated in Fig. 1. Here, chimeric rat/monkey $\mathrm{AO}$ was referred to one with rat type $2 \mathrm{Fe}-2 \mathrm{~S}$ and FAD domains and a monkey type MoCo domain, and chimeric rat/monkey $\mathrm{AO}$ was vice versa. Monkey and rat $\mathrm{AO}$ plasmids were extracted and purified from respective pQE-30 Xa vectors. They were treated with restriction enzyme $M f e I$ (New England Biolabs, Beverly, MA, U.S.A.) according to the manufacturer's instructions to obtain DNA fragments of $5.9 \mathrm{kbp}$ and $1.9 \mathrm{kbp}$. The $5.9 \mathrm{kbp}$ fragments, which are assumed to contain the MoCo domain, were dephosphorylated
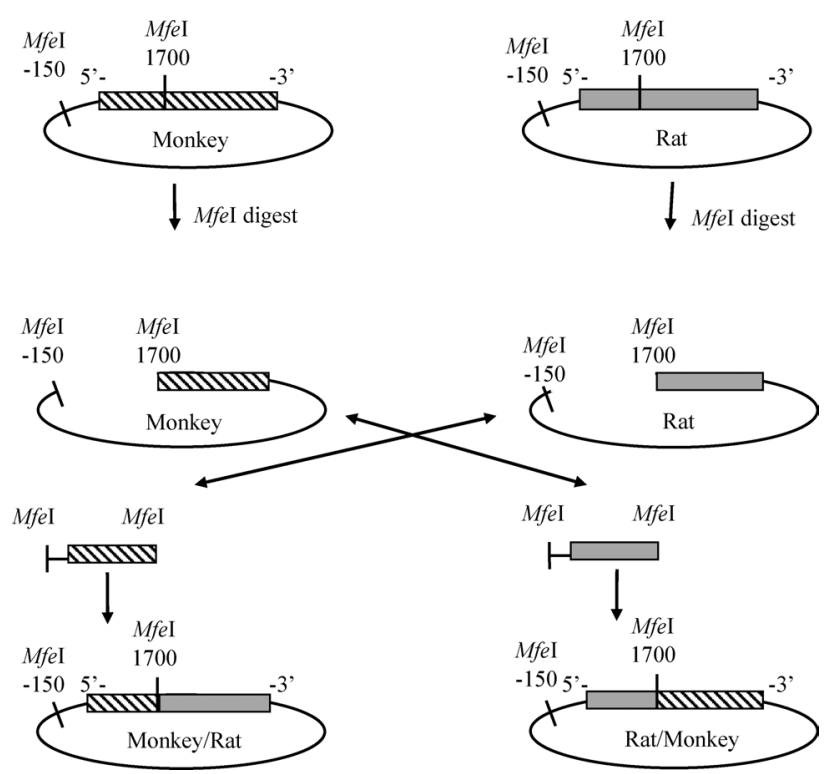

Fig. 1. Construction Strategy of Chimeric Monkey/Rat AO and Rat/Monkey AO

by PAP (Alkaline Phosphatase from Shewanella sp. SIB1) treatment according to the manufacturer's recommended protocol. The $1.9 \mathrm{kbp}$ fragments, which are assumed to contain the $2 \mathrm{Fe}-2 \mathrm{~S}$ and FAD domains, were purified with the Wizard SV Gel and PCR Clean-Up System. The monkey $1.9 \mathrm{kbp}$ fragment was ligated with the rat $5.9 \mathrm{kbp}$ fragment by using a TaKaRa DNA Ligation Kit Ver. 2.1 (TaKaRa Bio Inc., Kyoto, Japan), which was named the Monkey/Rat AO plasmid. Similarly, a Rat/Monkey AO plasmid was constructed by ligation of the rat $1.9 \mathrm{kbp}$ fragment with the monkey $5.9 \mathrm{kbp}$ fragment. The two AO cDNA plasmids were transfected into the expression Escherichia coli M15 cells (pREP4, QIAGEN). A single colony was cultured at $37^{\circ} \mathrm{C}$ overnight in $5 \mathrm{ml}$ of $2 \times$ YT medium containing $50 \mu \mathrm{g} / \mathrm{ml}$ ampicillin. Insertion of the respective AO cDNA was checked by agarose gel electrophoresis of Acc65I/SalI and SacI/HindIII treatment products. Then, the recombinant nucleotide sequences were determined by a CEQ 8000 Analysis System and a DTCS Quick Start Kit (Beckman-Coulter Inc., Fullerton, CA, U.S.A.) according to the method recommended by the manufacturer. The sequence primers used were $5^{\prime}$-agtcaccettgcaggttcagctc3' for Monkey/Rat AO and 5'-agtcaccttgcaggttcagctc-3' for Rat/Monkey AO, which were designed close to the $M f e I$ site.

Cell Cultures Each AO cDNA plasmid prepared above was transfected into the expression E. coli M15 cells. The control sample was produced by transfection of the pQE-30 $\mathrm{Xa}$ vector. A single colony was cultured at $37^{\circ} \mathrm{C}$ overnight in $5 \mathrm{ml}$ of LB medium containing $50 \mu \mathrm{g} / \mathrm{ml}$ ampicillin and $25 \mu \mathrm{g} / \mathrm{ml}$ kanamycin. To the overnight culture, $500 \mathrm{ml}$ of LB with $50 \mu \mathrm{g} / \mathrm{ml}$ ampicillin and $25 \mu \mathrm{g} / \mathrm{ml}$ kanamycin were added and cultured at $37^{\circ} \mathrm{C}$ until absorbance at $600 \mathrm{~nm}$ reached $0.5-0.6$. Then, IPTG $(1 \mathrm{~mm})$ was added to the mixture along with ATP $(1 \mathrm{~mm})$, riboflavin $(3 \mu \mathrm{M})$, and $\mathrm{Na}_{2} \mathrm{MoO}_{4}$ $(50 \mu \mathrm{M})$ according to the methods previously reported. ${ }^{27)}$ Growth of the culture was allowed to continue for $72 \mathrm{~h}$ at $22^{\circ} \mathrm{C}$. After collection by centrifugation at $7000 \mathrm{~g}$ for $10 \mathrm{~min}$ at $4{ }^{\circ} \mathrm{C}$, the cells were solubilized with QIAexpressionist (QIAGEN) according to the manufacturer's instructions. The 
soluble proteins were applied to a HisTrap HP Column (GE Healthcare Ltd., U.K., Buckinghamshire, England) fully preequilibrated with $10 \mathrm{~mm}$ phosphate buffer ( $\mathrm{pH}$ 7.4) containing $20 \mathrm{~mm}$ imidazole and $0.5 \mathrm{~m} \mathrm{NaCl}$ (Buffer A). After being washed with $100 \mathrm{~mm}$ imidazole in Buffer A, the objective enzyme was eluted with $250 \mathrm{~mm}$ imidazole in Buffer A.

Native-Polyacrylamide Gel Electrophoresis (PAGE) The expressed enzymes were separated by Native-PAGE, which was performed using NativePAGE Novex 4-16\% Bis-Tris Gel according to the manufacturer's protocol (Invitrogen Corp., Carlsbad, CA, U.S.A.). Protein bands were visible due to staining with the Coomassie G-250 in the sample additive and Cathode Buffer (Invitrogen). The NativeMark Unstained Protein Standard (Invitrogen) was used for the estimation of protein molecular mass; lactate dehydrogenase $146 \mathrm{kDa}$, B-phycoerythrin $242 \mathrm{kDa}$, apoferritin band $2480 \mathrm{kDa}$.

Statistical Analysis The results are expressed as the mean \pm S.E. of three to four experiments. Statistical significance was compared by Student's $t$-tests. Values with $p<0.05$ were considered statistically significant.

\section{RESULTS}

Native-PAGE The wild AO cDNA of monkey and rat and the chimeric AO cDNA of monkey/rat and rat/monkey were expressed and purified with a HisTrap column. The proteins obtained were analyzed by Native-PAGE (Fig. 2). All of them showed one band at the molecular mass of approximately $300 \mathrm{kDa}$.

AO Activity of Expressed Chimeric Enzymes The AO-catalyzed 2-oxidation activity of $(S)$-RS-8359 was measured using the expressed chimeric enzymes. Figure 3 shows a typical Michaelis-Menten plot. Monkey/rat AO exhibited a similar profile as that of rat $\mathrm{AO}$, in that a clear substrate inhibition was seen. In contrast, neither the rat/monkey AO nor the monkey AO showed any substrate inhibition. A typical Eadie-Hofstee plot is shown in Fig. 4. The monkey/rat AO exhibited a monophasic pattern in accord with that of rat AO. In contrast, a biphasic pattern was observed in the chimeric rat/monkey $\mathrm{AO}$ as well as in that of monkey $\mathrm{AO}$.

Kinetic Parameters of Expressed Chimeric Enzymes The kinetic parameters for 2-oxidation of $(S)$-RS-8359 were determined from Eadie-Hofstee plots (Table 1). A biphasic profile was observed in monkey $\mathrm{AO}$ and the chimeric rat/monkey $\mathrm{AO}$, but not in rat $\mathrm{AO}$ and the chimeric monkey/rat AO. When the parameters of monkey $\mathrm{AO}$ were compared with those of the chimeric rat/monkey $\mathrm{AO}$, it was

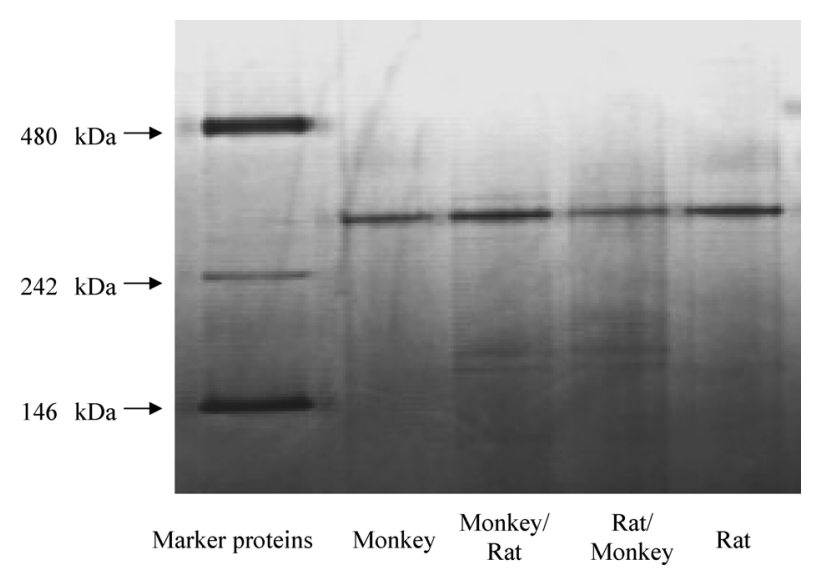

Fig. 2. Native-PAGE Analysis of AOs of Monkey, Rat, Chimeric Monkey/Rat, and Chimeric Rat/Monkey Expressed in E. coli

Native-PAGE was performed using Native-PAGE Novex 4-16\% Bis-Tris Gel according to the manufacturer's protocol. Protein bands were stained with the Coomassie G-250 in the sample additive and Cathode Buffer a) Monkey

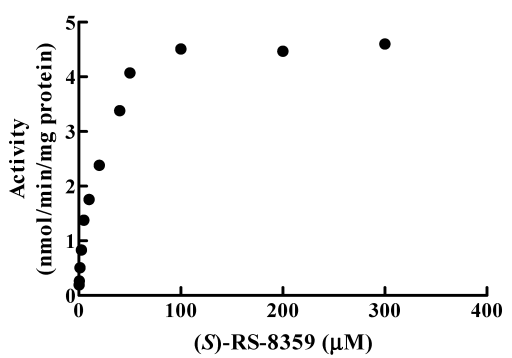

c) Monkey / Rat

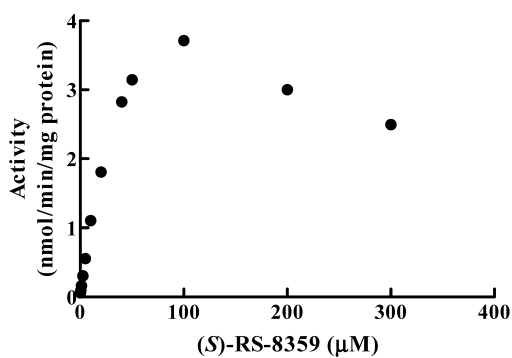

b) Rat

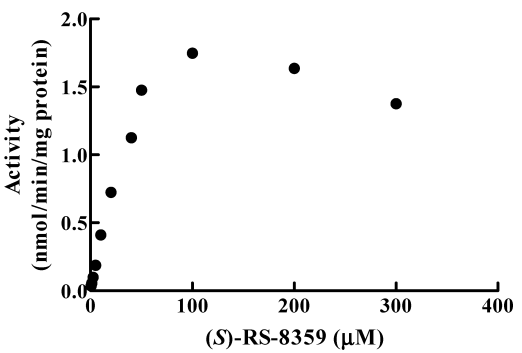

d) Rat / Monkey

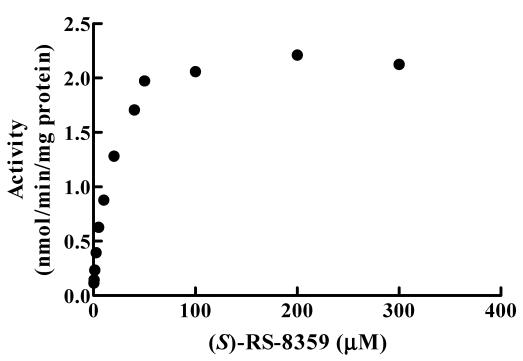

Fig. 3. Typical Michaelis-Menten Plots for AO-Catalyzed 2-Oxidation of (S)-RS-8359 by AOs of Monkey (a), Rat (b), Chimeric Monkey/Rat (c), and Chimeric Rat/Monkey (d) Expressed in E. coli

The typical result from at least three independent experiments is shown. The substrate concentrations were $0.313-300 \mu \mathrm{M}$. 
a) Monkey

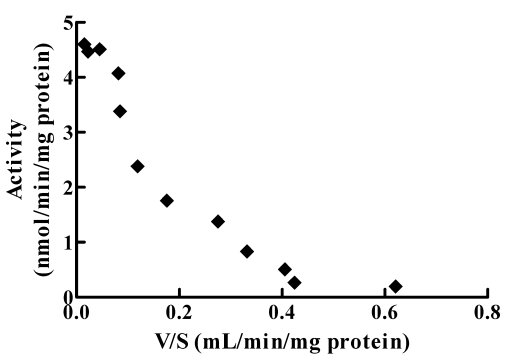

c) Monkey/Rat

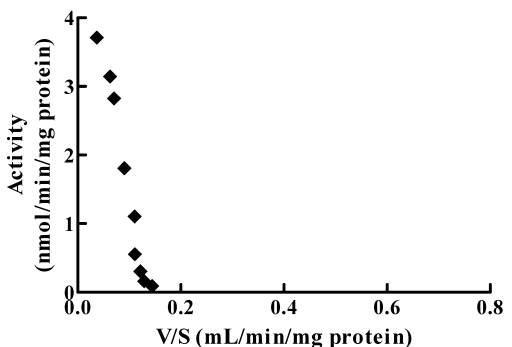

b) Rat

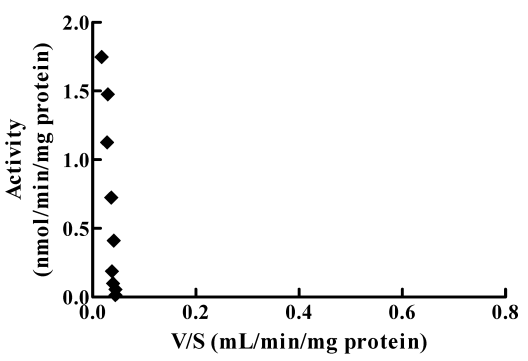

d) Rat/Monkey

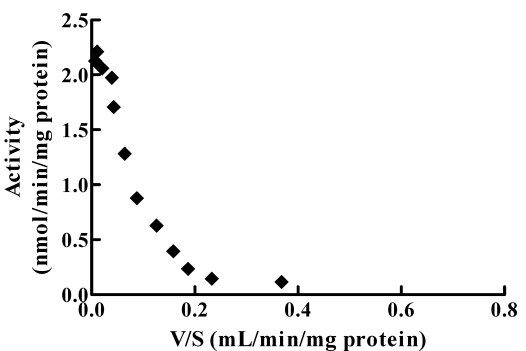

Fig. 4. Typical Eadie-Hofstee Plots for AO-Catalyzed 2-Oxidation of (S)-RS-8359 by AOs of Monkey (a), Rat (b), Chimeric Monkey/Rat (c), and Chimeric Rat/Monkey (d) Expressed in E. coli

The typical result from at least three independent experiments is shown. The substrate concentrations were $0.313-300 \mu \mathrm{M}$.

Table 1. Kinetic Parameters for 2-Oxidation of (S)-RS-8359 by AOs of Monkey, Rat, Chimeric Monkey/Rat, and Rat/Monkey Expressed in E. coli

\begin{tabular}{|c|c|c|c|c|}
\hline $\begin{array}{l}\text { Expressed } \\
\mathrm{AO}\end{array}$ & & $\begin{array}{c}K_{\mathrm{m}} \\
(\mu \mathrm{M})\end{array}$ & $\begin{array}{c}V_{\max } \\
(\mathrm{nmol} / \mathrm{min} / \mathrm{mg} \text { protein })\end{array}$ & $\begin{array}{c}C L_{\text {int }} \\
(\mu \mathrm{l} / \mathrm{min} / \mathrm{mg} \text { protein })\end{array}$ \\
\hline Monkey & High affinity & $3.51 \pm 1.00$ & $1.96 \pm 0.262$ & $637 \pm 182$ \\
\hline Monkey & Low affinity & $16.4 \pm 0.891$ & $4.88 \pm 0.231$ & $297 \pm 5.60$ \\
\hline Rat & & $52.8 \pm 8.67$ & $2.56 \pm 0.334$ & $49.7 \pm 6.52$ \\
\hline Monkey/rat & & $36.3 \pm 1.63$ & $5.10 \pm 0.556$ & $140 \pm 12.7$ \\
\hline Rat/monkey & High affinity & $4.43 \pm 1.23$ & $0.921 \pm 0.272$ & $283 \pm 157$ \\
\hline Rat/monkey & Low affinity & $17.1 \pm 1.29$ & $2.38 \pm 0.735$ & $148 \pm 58.3$ \\
\hline
\end{tabular}

Data represents the mean \pm S.E. of three to four experiments.

found that the $V_{\max }$ value of monkey AO was approximately two times greater than that of the corresponding rat/monkey AO for both the high and low affinity components. In contrast, the $K_{\mathrm{m}}$ value was nearly the same. Nearly the same twofold greater $V_{\max }$ value was observed for the chimeric monkey/rat $\mathrm{AO}$ compared to that of rat $\mathrm{AO}$ with no significant difference in $K_{\mathrm{m}}$ value.

\section{DISCUSSION}

$\mathrm{AO}$ activity is variable depending on species and substrate structures. Although many causes are plausible for the phenomenon, little is known. We supposed that differences in the structure of the $2 \mathrm{Fe}-2 \mathrm{~S} / \mathrm{FAD}$ domain and the substrate binding MoCo domain as possible causes. In order to obtain more information about these possibilities, chimeric rat/monkey $\mathrm{AO}$ and monkey/rat AO were constructed by exchanging the MoCo domain of AO cDNA between monkey and Donryu strain rat.

The monkey/rat AO as well as rat AO showed clear substrate inhibition at high concentrations in Michaelis-Menten plots for the AO-catalyzed 2-oxidation of $(S)$-RS-8359. In contrast, neither rat/monkey $\mathrm{AO}$ nor monkey $\mathrm{AO}$ exhibited any substrate inhibition. The substrate inhibition seen in rat liver cytosol was reproduced in the chimeric monkey/rat AO enzyme, suggesting that the MoCo domain, which contains a substrate binding site, was obviously involved in the phenomenon. In contrast, no substrate inhibition was observed for liver cytosol of human and rabbit that show relatively high AO activity. The oxidation of quinoline and quinolinebased alkaloids with hepatic AO of rabbit and guinea pig exhibited substrate inhibition. The phenomenon was explained as following: the excess substrate molecules are able to bind at a second low-affinity binding site, thus inhibiting oxidation of substrates bound at the primary high-affinity site. ${ }^{36)}$ Obach. ${ }^{37)}$ reported that vanillin and nicotine- $\Delta 1^{\prime}\left(5^{\prime}\right)$ iminium ion oxidations catalyzed by human liver cytosolic AO followed simple Michaelis-Menten kinetics, whereas the two reactions of phthalazine oxidation and CP-544, 439 reduction demonstrated substrate inhibition. These findings suggest that substrate inhibition is not related to the degree of AO activity, animal species, the direction of reaction, and the chemical structure of the substrate, in other words being variable depending on species and chemical structure. Organized studies are needed for clarification of the detailed mechanism. 
Eadie-Hofstee plots for the 2-oxidation activity of $(S)$-RS8359 demonstrated the biphasic pattern for monkey $\mathrm{AO}$ and the chimeric rat/monkey $\mathrm{AO}$, but not for rat $\mathrm{AO}$ and the chimeric monkey/rat AO. Usually, a biphasic pattern is caused by the existence of two enzymes catalyzing the same reaction or by the existence of two binding sites in a single enzyme. In the current study, we used the AO enzyme obtained by expression of a single AO gene. The enzyme was actually a single band on Native-PAGE/Western blot analysis. Accordingly, it is strongly suggested that the biphasic EadieHofstee profile was caused by two binding sites in a single enzyme. Taylor et al. ${ }^{38)}$ studied the product ratio of 2- to 4quinolone metabolites from $N$-methylquinolinium salts with rabbit or guinea pig liver AO. From a change in the production ratio at high $\mathrm{pH}$ values and in the presence of a competing substrate, they suggested the possibility of two binding sites for a quaternary substrate. Details of the binding sites will be one of the future subjects of investigation.

The $V_{\max }$ values for the AO-catalyzed 2-oxidation of $(S)$ RS-8359 of high and low affinity components in monkey AO were approximately two times greater than that in the chimeric rat/monkey AO. Similarly, the $V_{\max }$ value was approximately two times greater in the chimeric monkey/rat $\mathrm{AO}$ than that in rat AO. However, there were no significant differences in $K_{\mathrm{m}}$ values between the AOs. The results indicated that the monkey type of $2 \mathrm{Fe}-2 \mathrm{~S} / \mathrm{FAD}$ domain gives a higher velocity compared to the corresponding rat type when the MoCo domain is identical. This might be caused by a more effective electron transfer system in monkey than in rat, and the difference in the system might be one reason for the species differences in AO. However, the results do not necessarily explain remarkable species differences in AO activity observed in the 2-oxidation of $(S)$-RS-8359. ${ }^{16)}$ They rather suggest that AO activity itself is not so much different between monkey and rat, and an another reason, for example the amount of $\mathrm{AO}$ expressed in the liver, is mainly responsible for the species difference. We are now investigating which of the $2 \mathrm{Fe}-2 \mathrm{~S}$ and FAD domains contributes more to the enhancement of $\mathrm{AO}$ activity or whether both of them are needed as well as quantitative evaluation of the enzyme in the liver cytosols.

In conclusion, the chimeric $\mathrm{AO}$ enzymes of monkey and Donryu strain rat were expressed in E. coli and the AO-catalyzed 2-oxidation activities of $(S)$-RS-8359 were measured. It was suggested that the phenomena of substrate inhibition and biphasic Eadie-Hofstee profile observed in rat and monkey, respectively, is primarily dependent on the properties of each animal's MoCo domain. Further, the difference in electron transfer efficiency in the $2 \mathrm{Fe}-2 \mathrm{~S} / \mathrm{FAD}$ domain was suggested to partly contribute to species difference in AO activity.

\section{REFERENCES}

1) Garattini E., Fratelli M., Terao M., Cell. Mol. Life Sci., 65, 10191048 (2008).

2) Beedham C., Drug Metab. Rev., 16, 119-156 (1985).

3) Beedham C., Prog. Med. Chem., 24, 85-121 (1987).

4) Beedham C., Pharm. World Sci., 19, 255-263 (1997).

5) Beedham C., "Enzyme Systems That Metabolise Drug and Other Xenobiotics," ed. by Ioannides C., John Wiley, London, 2002, pp.
$147-187$.

6) Kitamura S., Sugihara K., Ohta S., Drug Metab. Pharmacokinet., 21, 83-98 (2006).

7) Prakash C., Kamel A., Gummerus J., Wilner K., Drug Metab. Dispos., 25, 863-875 (1997).

8) Beedham C., Miceli J. J., Obach S., J. Clin. Psychopharm., 23, 229232 (2003).

9) Acheampong A. A., Chien D.-S., Lam S., Vekich S., Breau A., Usansky J., Harcourt D., Munk S. A., Nguyen H., Garst M., Tang-Liu D., Xenobiotica, 26, 1035-1055 (1996).

10) Rashidi M. R., Smith J. A., Clarke S. E., Beedham C., Drug Metab. Dispos., 25, 805-813 (1997).

11) Kitamura S., Sugihara K., Nakatani K., Ohta S., O’Hara T., Nimomiya S., Green C. E., Tyson C. A., UBMB Life, 48, 607-611 (1999).

12) Kawashima K., Hosoi K., Naruke T., Shiba T., Kitamura M., Watabe T., Drug Metab. Dispos., 27, 422-428 (1999).

13) Klecker R. W., Cysyk R. L., Collins J. M., Bioorg. Med. Chem., 14, 62-66 (2006)

14) Takasaki W., Yamamura M., Nozaki A., Nitanai T., Sasahara K., Itoh K., Tanaka Y., Chirality, 17, 135-141 (2005).

15) Itoh K., Yamamura M., Muramatsu S., Hoshino K., Masubuchi A., Sasaki T., Tanaka Y., Xenobiotica, 35, 561—573 (2005).

16) Itoh K., Yamamura M., Takasaki W., Sasaki T., Masubuchi A., Tanaka Y., Biopharm. Drug Dispos., 27, 1133-1139 (2006).

17) Itoh K., Masubuchi A., Sasaki T., Adachi M., Watanabe N., Nagata K., Yamazoe Y., Hiratsuka M., Mizugaki M., Tanaka Y., Drug Metab. Dispos., 35, 351-356 (2007).

18) Itoh K., Maruyama H., Adachi M., Hoshino K., Watanabe N., Tanaka Y., Xenobiotica, 37, 709-716 (2007).

19) Yokoyama T., Karube T., Iwata N., J. Pharm. Pharmacol., 41, 32-36 (1989).

20) Miura H., Naoi M., Nakahara D., Ohta T., Nagatsu T., J. Neural. Transm., 94, 175-187 (1993).

21) Plenker A., Puchler K., Volz H. P., Int. Clin. Psychopharm., 12, S25S29 (1997).

22) Puchler K., Schaffler K., Plenker A., Int. Clin. Psychopharm., 12, S17-S23 (1997)

23) Hoshino K., Itoh K., Masubuchi A., Adachi M., Watanabe N., Kosaka T., Tanaka Y., Biol. Pharm. Bull., 30, 1191-1198 (2007).

24) Kurosaki M., Demontis S., Barzago M. M., Garattini E., Terao M., Biochem. J., 341, 71-80 (1999).

25) Terao M., Kurosaki M., Saltini G., Demontis S., Marini M., Salmona M., Garattini E., J. Biochem. Chem., 275, 30690-30700 (2000).

26) Wright R. M., Clayton D. A., Riley M. G., McManaman J. L., Repine J. E., J. Biochem. Chem., 274, 3878-3886 (1999).

27) Huang D. Y., Furukawa A., Ichikawa Y., Arch. Biochem. Biophys., 364 264-272 (1999)

28) Calzi M., Raviolo C., Ghibaudi E., Gioia L. D., Salmona M., Cazzaniga G., Kurosaki M., Terao M., Garattini E., J. Biochem. Chem., 270, 31037-31045 (1995).

29) Wright R. M., Vaitaitis G. M., Wilson C. M., Repine T. B., Terada L. S., Repine J. E., Proc. Natl. Acad. Sci. U.S.A., 90, 10690-10694 (1993).

30) Berger R., Mezey E., Clancy K. P., Harta G., Wright R. M., Repine J E., Brown R. H., Brownstein M., Patterson D., Somat. Cell Mol. Genet., 21, 121-131 (1995).

31) Turner N. A., Doyle W. A., Ventom A. M., Bray R. C., Eur. J. Biochem., 232, 646-657 (1995).

32) Terao M., Kurosaki M., Demontis S., Zanotta S., Garattini E., Biochem. J., 332, 383-393 (1998).

33) Demontis S., Kurosaki M., Saccone S., Motta S., Garattini E., Terao M., Biochem. Biophys. Acta, 1489, 207-222 (1999).

34) Korzekwa K. R., Krishnamachary N., Shou M., Ogai A., Parise R. A., Rettie A. E., Gonzalez F. J., Tracy T. S., Biochemistry, 37, 4137-4147 (1998).

35) Adachi M., Itoh K., Masubuchi A., Watanabe N., Tanaka Y., J. Biochem. Mol. Biol., 40, 1021-1027 (2007).

36) Beedham C., Al-Tayib Y., Smith J. A., Drug Metab. Dispos., 20, 889895 (1992).

37) Obach R. S., Drug Metab. Dispos., 32, 89—97 (2004).

38) Taylor S. M., Beedham C., Stell J. G. P., Biocem. J., 220, 67-74 (1984). 